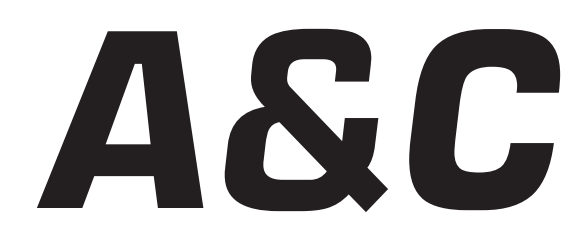

Revista de Direito Administrativo \& Constitucional

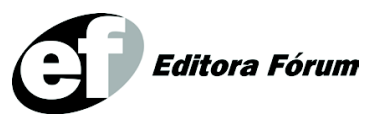

ISSN 1516-3210 


\section{A\&C REVISTA DE DIREITO ADMINISTRATIVO E CONSTITUCIONAL}

IPDA

Instituto Paranaense

de Direito Administrativo

Direção Geral

Romeu Felipe Bacellar Filho

Direção Editorial

Paulo Roberto Ferreira Motta

Direção Executiva

Emerson Gabardo

Conselho de Redação

Edgar Chiuratto Guimarães

Adriana da Costa Ricardo Schier

Célio Heitor Guimarães

\section{Conselho Editorial}

Adilson Abreu Dallari

Alice Gonzáles Borges

Carlos Ari Sundfeld

Carlos Ayres Britto

Carlos Delpiazzo

Cármen Lúcia Antunes Rocha

Celso Antônio Bandeira de Mello

Clèmerson Merlin Clève

Clóvis Beznos

Enrique Silva Cimma

Eros Roberto Grau

Fabrício Motta

Guilhermo Andrés Muñoz (in memoriam)

Jaime Rodríguez-Arana Muñoz

Jorge Luís Salomoni

José Carlos Abraão
José Eduardo Martins Cardoso
José Luís Said
José Mario Serrate Paz
Juan Pablo Cajarville Peruffo
Juarez Freitas
Julio Rodolfo Comadira
Luís Enrique Chase Plate
Lúcia Valle Figueiredo
Manoel de Oliveira Franco Sobrinho
(in memoriam)
Marçal Justen Filho
Marcelo Figueiredo
Márcio Cammarosano
Maria Cristina Cesar de Oliveira

Nelson Figueiredo

Odilon Borges Junior

Pascual Caiella

Paulo Eduardo Garrido Modesto

Paulo Henrique Blasi

Paulo Neves de Carvalho (in memoriam)

Paulo Ricardo Schier

Pedro Paulo de Almeida Dutra

Regina Maria Macedo Nery Ferrari

Rogério Gesta Leal

Rolando Pantoja Bauzá

Sérgio Ferraz

Valmir Pontes Filho

Yara Stropa

Weida Zancaner

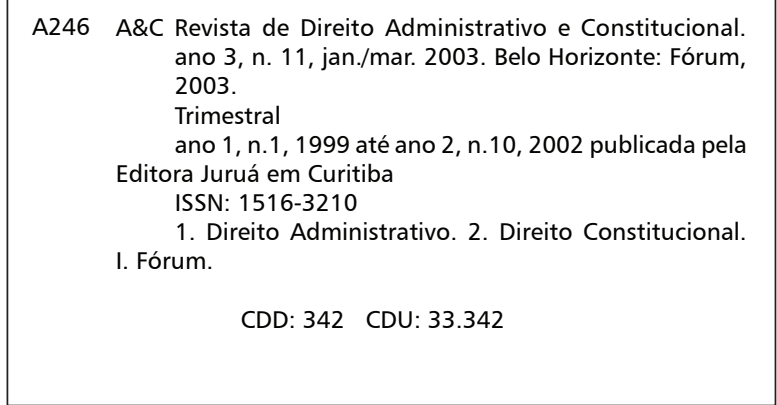

(C) Editora Fórum Ltda. 2007

Todos os direitos reservados. É proibida a reprodução total ou parcial, de qualquer forma ou por qualquer meio eletrônico ou mecânico, inclusive através de processos xerográficos, de fotocópias ou de gravação, sem permissão por escrito do possuidor dos direitos de cópias (Lei nº 9.610, de 19.02.1998).

Editora Fórum Ltda

Av. Afonso Pena, 2770 - 15\%16ª andar - Funcionários

CEP 30130-007 - Belo Horizonte/MG - Brasil

Tel.: 08007043737

Internet: www.editoraforum.com.br

e-mail: editoraforum@editoraforum.com.br
Editor responsável: Luís Cláudio Rodrigues Ferreira Projeto gráfico e diagramação: Luis Alberto Pimenta Revisora: Olga M. A. Sousa

Pesquisa jurídica: Fátima Ribeiro - OAB/MG 74868

Bibliotecária: Alessandra Rodrigues da Silva CRB 2778/MG 6 ${ }^{\text {a Região }}$

Os conceitos e opiniões expressas nos trabalhos assinados são de responsabilidade exclusiva de seus autores.

Impressa no Brasil / Printed in Brazil

Distribuída em todo Território Nacional 


\title{
El Derecho Público Colombiano
}

\author{
Jorge Enrique Ibáñez Najar \\ Profesor de Derecho Constitucional y de Derecho Administrativo de las Universidades Javeriana, \\ Los Andes, Externado, Sergio Arboleda y Santo Tomás de Bogotá, Colombia.
}

Palabras clave: Derecho constitucional. Derecho administrativo. Colombia.

Sumario: I Las relaciones entre el Derecho Constitucional y el Derecho Administrativo en Colombia - II Análisis sobre la proyección del modelo de Estado en el conjunto del Derecho Administrativo colombiano - III Los fines esenciales del Estado y los principales principios y criterios constitucionales que afectan al Derecho Administrativo - IV Análisis de las instituciones del Derecho Administrativo que han sido elevadas a rango constitucional - Bibliografía

\section{Las relaciones entre el Derecho Constitucional y el Derecho Administrativo en Colombia}

Por regla general, para el derecho constitucional, la Constitución Política de un Estado es el punto de llegada. En ella finalmente se hace la síntesis de los fines de la comunidad asentada en un determinado territorio y políticamente soberana y establecen las autoridades a cuyo cargo estarán las distintas funciones públicas para el ejercicio del poder público. A su vez, como generalmente ocurre con la estructuración de su parte dogmática, en ella se consagran de manera enunciativa los principios que rigen a la comunidad y a sus autoridades, los derechos que deben ser respetados y cuya efectividad se garantiza o se propone y los deberes a cargo de las personas. En todo caso, el objeto de estudio del derecho constitucional no es únicamente la Constitución, pues ésta apenas constituye una mínima parte. Lo esencial está en el estudio de los sistemas políticos, los sistemas electorales, los sistemas de gobierno, los sistemas económicos y sociales, los sistemas judiciales, las formas de Estado, la evolución y el funcionamiento de los Estados, la función constituyente, las funciones públicas y la estructura de su organización para cumplirlas. Con base en todos ellos, cada comunidad política adopta los sistemas que mejor le convengan o diseña el que mejor se acomode a sus necesidades, todo lo cual finalmente se construye cuando se adopta la Constitución Política del Estado unitario o la Constitución Nacional y las constituciones subnacionales de los estados compuestos. En definitiva, la Constitución Política de un Estado contiene la síntesis de las ideas que más se acomodan a su comunidad política.

A \& C R. de Dir. Administrativo e Constitucional, Belo Horizonte, ano 7, n. 28, p. 167-193, abr./jun. 2007 
Para el derecho administrativo, en cambio, la Constitución Política es el punto de partida, lo cual significa que él se construye en cada Estado a partir de lo que se ha definido en la Constitución. Por ello, no puede abordarse el estudio del derecho administrativo, si previamente no se ha hecho el estudio del derecho constitucional, tanto general como particular, así como no puede ejercerse la función administrativa y por lo mismo cumplirse ninguna actividad administrativa, si previamente no se saben los límites, los alcances y los contenidos definidos en la Constitución para ello. De allí que, sin derecho constitucional, no puede existir derecho administrativo. A su vez, el sólo derecho constitucional es insuficiente si no se concreta con el estudio y práxis del derecho administrativo, el cual precisamente tiene por objeto desarrollar el derecho constitucional.

La Constitución Política traza las reglas generales, define las funciones esenciales, prevé los principios para cumplirlas y, de manera general, determina la gran estructura estatal para su ejercicio. La ley y el acto administrativo normativo, sea regulador o reglamentario, tienen por objeto desarrollar tales reglas, precisar tales funciones y concretar dicha estructura. La actividad administrativa se desarrolla mediante actuaciones administrativas que, con sujeción a los procedimientos previstos en la ley, culminan con la expedición de actos administrativos -sean ellos unilaterales, consensuales, concertados o participativos- o la celebración y ejecución de contratos estatales; mediante la ejecución de operaciones administrativas o mediante hechos de la administración, a través de los cuales se cumplen los cometidos estatales.

Así, uno y otro, derecho constitucional y derecho administrativo configuran una unidad indisoluble e inseparable: el derecho público. Por ello, no hay derecho administrativo sin derecho constitucional ni puede existir derecho constitucional sin derecho administrativo.

Este es el caso colombiano, en el cual el derecho constitucional no sólo constituye la fuente principal del derecho administrativo sino que, como parte que es del derecho público, constituye una unidad inseparable con el derecho administrativo, a tal punto que este constituye la prolongación de aquel, sin perjuicio, claro está, de la actividad jurisdiccional, la cual tiene a su cargo, en buena parte, a través tanto del tribunal constitucional como del tribunal supremo de lo contencioso administrativo, ejercer el control judicial de la actividad pública, la cual es expresión de la función constituyente derivada y de las funciones legislativa y administrativa.

A \& C R. de Dir. Administrativo e Constitucional, Belo Horizonte, ano 7, n. 28, p. 167-193, abr./jun. 2007 


\section{Análisis sobre la proyección del modelo de Estado en el conjunto del Derecho Administrativo colombiano}

Colombia, cuenta con un vasto territorio, en el cual - de acuerdo con las proyecciones hechas desde el último censo poblacional -, al promediar el sexto año del Siglo XXI, viven en él aproximadamente 47.5 millones de personas, de las cuales casi 23 millones son hombres y 24.5 son mujeres; 35 es población urbana y 12.5 población rural. De ellas, 24.7 millones de ciudadanos integran el Censo Electoral, aunque sólo participan en promedio 13 millones de ciudadanos colombianos, esto es, menos de una tercera parte de sus habitantes.

A su vez, para dirigir los destinos de esta gran nación, el Estado, entendido como la Administración Pública, está integrado por una Administración Nacional y una Administración Territorial. Dicha Administración Pública se compone de un conjunto de personas jurídicas de derecho público para el ejercicio de múltiples funciones públicas previstas en la Constitución y en la Ley, sin perjuicio de las personas jurídicas de derecho privado a las cuales el ordenamiento jurídico les atribuye también el ejercicio de funciones públicas.

A) Las nuevas funciones públicas y la estructura del Estado para cumplirlas

A partir de 1991, en Colombia existe una nueva concepción del Estado, de sus principios, de sus fines, de sus funciones y de su estructura.

En efecto, además de la función constituyente y de las funciones derivadas legislativa, administrativa y jurisdiccional, se han desarrollado otras como la función genérica de control o fiscalización que a su vez comprende las funciones especiales de inspección y vigilancia, de control interno, de control fiscal, de control público y de control político; igualmente, se ha hecho un mejor tratamiento y desarrollo de las funciones electoral y de seguridad y defensa nacional, al tiempo que se ha consagrado constitucionalmente la función de banca central.

El ejercicio de las funciones tradicionales se ha ampliado en forma considerable, pues existen nuevos mecanismos de regulación, dirección e intervención de las autoridades estatales en toda clase de actividades. Por su parte, la ampliación de los fines del Estado, les impuso a las autoridades desarrollar un nuevo marco de gestión de la administración que incluye la adopción de políticas públicas y su ejecución en función de resultados tanto para garantizar la prestación eficiente de los servicios públicos como para satisfacer las necesidades básicas de la población.

A \& C R. de Dir. Administrativo e Constitucional, Belo Horizonte, ano 7, n. 28, p. 167-193, abr./jun. 2007 
$\mathrm{Al}$ aumento de funciones ha correspondido un número mayor de entidades públicas o la ampliación de las existentes.

Para tal efecto, la Constitución Política de 1991, adoptó una nueva estructura general del Estado Colombiano compuesta por las tradicionales tres grandes Ramas del Poder Público, esto es, la Rama Legislativa, la Rama Ejecutiva y la Rama Jurisdiccional (Art. 113) y por dos nuevas Organizaciones a saber: La Organización Fiscalizadora o de Control, para el ejercicio de las funciones tanto de Ministerio Público como de control sobre la gestión fiscal (Arts. 113, 117 a 119) y la Organización Electoral para el cumplimiento de las funciones públicas relacionadas con el sistema electoral (Arts. 113, 120). Así mismo, consagró como órganos autónomos de carácter constitucional a entidades como el Banco de la República para el ejercicio de la moderna función de banca central (Arts. 371 a 373) y a la Comisión Nacional de Televisión (arts. 75 y 76) para ejercer las funciones administrativas de intervención en el espectro electromagnético y la definición de la política pública en materia de televisión. Posteriores decisiones judiciales de la Corte Constitucional ampliaron tal estructura estatal al definir que también son órganos autónomos con régimen constitucional especial la Comisión Nacional del Servicio Civil para la administración de las carreras administrativas (Art. 130), las Corporaciones Autónomas Regionales para el cumplimiento de determinadas funciones de carácter ambiental (arts. 150-7 y 331) y las universidades oficiales para la prestación del servicio público de educación superior (art. 69).

Con fundamento en dicha estructura general, la misma Constitución Política de 1991, creó o autorizó la creación de más entidades en cada una de las Ramas del Poder Público, le dio autonomía a otras y creó más entes autónomos. Así, por ejemplo, en la Rama Judicial creó la Corte Constitucional, el Consejo Superior de la Judicatura, con sus dos Salas Administrativa y Jurisdiccional y los Consejos Seccionales y la Fiscalía General de la Nación. En el Ministerio Público que hace parte de la organización Fiscalizadora o de Control, creó la Defensoría del Pueblo, la cual depende funcionalmente de la Procuraduría General de la Nación para la defensa y protección de los derechos humanos. En esa misma organización creó la Auditoría General de la República para ejercer el control sobre la gestión fiscal de la Contraloría General de la República. En la Rama Ejecutiva del Poder Público creó Superintendencia de Servicios 
Públicos Domiciliarios, la Contaduría General de la Nación, las Oficinas de Control Interno en todas las entidades y organismos públicos, la categoría de empresas prestadoras de servicios públicos y la categoría de empresas sociales del Estado. Igualmente, le dio autonomía especial a la Contraloría General de la República, a la Procuraduría General de la Nación, al Consejo Nacional Electoral y a la Registraduría Nacional del Estado Civil.

De esta manera, en cuanto se refiere a los órganos que integran la Rama Legislativa del Poder Público, Colombia cuenta con un Congreso de la República integrado por el Senado de la República con 102 miembros ${ }^{1}$ y la Cámara de Representantes integrada por 167 miembros, los cuales se distribuyen en cada Cámara, en siete Comisiones Constitucionales Permanentes, en Comisiones Legales, en Comisiones de Seguimiento y en Comisiones Especiales. Cada senador y cada representante cuenta, así mismo, con una Unidad Legislativa. Una y otra Corporación legislativa cuenta, además, cada una, con una estructura administrativa.

En lo que respecta a la Rama Ejecutiva del Poder Público que es la encargada principalmente del cumplimiento de las funciones de carácter administrativo, la Constitución Política prevé la existencia de dos grandes niveles: el orden nacional, con sus sectores central y descentralizado funcionalmente o por servicios y, el orden territorial, que como se verá más adelante, está compuesto a su vez por varias clases de entidades, a saber: Las entidades territoriales, las entidades administrativas especiales, las entidades descentralizadas por servicios de las entidades territoriales y los territorios indígenas.

En esta materia debe decirse que ahora la Constitución Política prácticamente diseñó la estructura de la Rama Ejecutiva del Poder Público en el orden nacional, al definir las siguientes categorías de entidades que en ella deben existir: La Presidencia de la República (Arts. 196, 199, 203); la Vicepresidencia de la República (Art. 202); los Consejos Superiores de la Administración (Art. 150-7); los Ministerios (Arts. 150-7, 189, 206); los Departamentos Administrativos (Arts. 115, 150-7, 189, 206); las Superintendencias (Arts. 115, 150-7); los Establecimientos Públicos (Arts. 150-7, 189); las Empresas Industriales y Comerciales del Estado (Arts.

${ }^{1}$ Cien de ellos elegidos en circunscripción nacional y dos en circunscripción especial indígena.

A \& C R. de Dir. Administrativo e Constitucional, Belo Horizonte, ano 7, n. 28, p. 167-193, abr./jun. 2007 
115, 150-7, 154); las Empresas Sociales del Estado (Arts. 48, 49 y 365); las Sociedades de Economía Mixta (Art. 150-7); las empresas estatales prestadoras de servicios públicos (Arts. 365, 369, 370) y otras entidades y organismos administrativos del orden nacional (Art. 150-7, 189-15, 16).

Desde luego que la Constitución Política solo prevé categorías de instituciones y faculta al legislador para crear otras, pero deja en manos del legislador, a iniciativa del Gobierno, la facultad para crear, dentro de cada una de ellas, las entidades que se requieran para el cumplimiento de las funciones que se les atribuyan. Igualmente, faculta al legislador, también a iniciativa del Gobierno, para fusionar o suprimir tales entidades, sin perjuicio de la facultad que también le confiere al Presidente de la República para hacerlo de conformidad con la ley (art.189-15) o para modificar sus estructuras con sujeción a los principios y reglas generales que defina la ley (art. 189-16).

Se trata en todo caso de una estructura abierta, con la posibilidad de ampliarla para el cumplimiento de los fines del Estado, mediante normas ordinarias, lo cual garantiza la flexibilidad que se requiera para atender a los cambios que demanden las circunstancias.

Por su parte, la Rama Jurisdiccional agrupa un número considerable de despachos judiciales distribuidos en cuatro clases de jurisdicciones, así:

- La Jurisdicción Ordinaria, con la Corte Suprema de Justicia a la cabeza como tribunal de Casación, los Tribunales Superiores de Distrito Judicial, los Juzgados de Circuito y los Juzgados Municipales;

- La Jurisdicción Constitucional, con la Corte Constitucional como órgano principal y el Consejo de Estado, para el ejercicio residual de algunas funciones de control constitucional;

- La Jurisdicción Contencioso Administrativa, con el Consejo de Estado como tribunal supremo de esa jurisdicción, los Tribunales Administrativos y los Juzgados Administrativos; y,

- Las jurisdicciones especiales conformadas por los jueces de paz y las autoridades de los pueblos indígenas.

Así mismo, forman parte de la Rama Judicial, el Consejo Superior de la Judicatura, con sus dos Salas - Administrativa y Jurisdiccional Disciplinaria- y sus respectivos Consejos Seccionales, distribuidos también en dos salas de la misma naturaleza, y la Fiscalía General de la Nación.

A su vez, la Organización Fiscalizadora o de control está integrada

A \& C R. de Dir. Administrativo e Constitucional, Belo Horizonte, ano 7, n. 28, p. 167-193, abr./jun. 2007 
por los órganos que integran el Ministerio Público y los órganos de control fiscal.

El Ministerio Público está integrado en el orden nacional por la Procuraduría General de la Nación y por la Defensoría del Pueblo; una y otra entidades, tienen una gran estructura, que se distribuye entre el Despacho del Procurador General que comprende los de los Procuradores Auxiliares, el Despacho del Viceprocurador, las Procuradurías Delegadas para la Vigilancia de las funciones públicas, las Procuradurías delegadas ante las autoridades jurisdiccionales, las Procuradurías Regionales, las Procuradurías Provinciales, el Despacho del Defensor del Pueblo, las Defensorías Delegadas y las Defensorías Regionales y Provinciales. A esta infraestructura se agregan 1.101 personerías distritales y municipales.

Las entidades que tienen a su cargo el cumplimiento de funciones de control fiscal sobre la gestión fiscal de la administración pública son la Contraloría General de la República, la Auditoría General de la República, las Contralorías Departamentales, las Contralorías Distritales y las Contralorías Municipales.

La Organización de las autoridades electorales comprende el Consejo Nacional Electoral, la Registraduría Nacional del Estado Civil, las Registradurías Departamentales y las Registradurías Distritales y Municipales.

Finalmente, existe un conjunto de entidades autónomas, con personería jurídica y autonomía administrativa, patrimonial y técnica para el cumplimiento de algunas funciones a cargo del Estado, a saber:

Para el cumplimiento de la función de banca central y otras funciones -algunas complementarias como las relativas a la acuñación e impresión de las especies monetarias- y otras como las de carácter cultural, está el Banco de la República, que es una persona jurídica de derecho público, con autonomía plena autonomía respecto del Gobierno y con régimen constitucional y legal propio, que cuenta con una Junta Directiva -que es la autoridad monetaria, cambiaria y crediticia del Estado- y su Consejo de Administración.

Para la intervención en el espectro electromagnético y la definición de la política de televisión, existe la Comisión Nacional de Televisión, que es también una entidad de derecho público, con autonomía administrativa, patrimonial y técnica, sujeta a un régimen constitucional y legal propio.

Para la administración de los sistemas de carrera administrativa,

A \& C R. de Dir. Administrativo e Constitucional, Belo Horizonte, ano 7, n. 28, p. 167-193, abr./jun. 2007 
existe la Comisión Nacional del Servicio Civil, la que por mandato del tribunal constitucional se ha organizado como una persona jurídica de carácter autónomo y con régimen especial.

Finalmente existen las Corporaciones Autónomas Regionales y las Universidades oficiales también organizadas como entes autónomos de derecho público, con un régimen especial tanto de rango constitucional como de carácter legal.

B) La forma de Estado y la estructura del orden territorial

Uno de los temas más importantes del régimen constitucional lo constituye el de la Estructura del Estado y dentro de éste, el relacionado con el régimen jurídico, político, administrativo y fiscal de sus entidades territoriales. Con él se desarrolla el tema de la forma de organización administrativa de un Estado y se define su orientación: federal, semifederal, confederal, autonómico, central, descentralizado, concentrado o desconcentrado.

Entonces, una de las grandes decisiones de cualquier régimen constitucional consiste en definir su forma de organización administrativa. Por ello, el sistema constitucional colombiano históricamente se enmarca en unos períodos en los cuales ha tomado partido acerca de un determinado sistema de organización política y administrativa: La federación y el centralismo, en los albores de la República; el centralismo, una vez constituida ésta luego de libradas las batallas de independencia y aún, después de producida la separación de las naciones que originalmente constituyeron la República; la federación y luego la confederación, hasta el restablecimiento de la República Unitaria, con centralización política pero descentralización administrativa, la cual perduró un Siglo; luego, el corto período en el cual se rompió parcialmente la centralización política hasta 1991, cuando se expidió la Constitución que actualmente rige y consagró en él un conjunto de normas sobre ordenamiento territorial.

En efecto, a partir de la independencia colombiana, hace casi dos siglos, tratando de crear una República o un Estado Federal, Colombia terminó en una confederación de pequeñas y débiles provincias absolutamente incapaces de sostener el proceso emancipador. Por ello el consabido mote de "La Patria Boba" que los historiadores le dieron al período 1810 a 1814, que está comprendido entre las declaraciones de independencia y la reconquista española.

Posteriormente, entre 1819 y 1821 , Colombia giró hasta el otro

A \& C R. de Dir. Administrativo e Constitucional, Belo Horizonte, ano 7, n. 28, p. 167-193, abr./jun. 2007 
extremo y creó una "Gran República”, que también los historiadores registran como "La Gran Colombia" y que nosotros llamaremos, la Primera República, pero que en medio de su grandeza de disolvió más pronto de lo esperado, en 1830.

Solos, a partir de 1832, los colombianos iniciaron un nuevo proceso hacia la consolidación de la República de la Nueva Granada y que nosotros llamaremos la Segunda República y, cuando estuvieron a punto lograrlo, otra vez, desembocaron en una confederación (1854-1858) y posteriormente en un Estado Federal (1863), que en todo caso no pudo consolidarse de manera definitiva.

Por ello, a partir de 1885, los colombianos se dieron a la tarea de restablecer la República la que se consolidó a partir de 1886, en lo que se podría denominar la Tercera República, año en el cual se le dio al Estado el carácter de unitario con centralización política y descentralización administrativa -fuere funcional, por servicios o territorial-, y cuya vigencia perduró hasta el año de 1991.

Finalmente, en el año de 1991, la Asamblea Nacional Constituyente convocada por el pueblo colombiano para expedir una nueva Constitución Política, aunque estudió propuestas para transformar la forma de Estado -en un Estado Autonómico, en un Estado Regional, en un Estado Semifederal- o para conservarlo como Estado unitario, mantuvo la misma forma de Estado pero le introdujo algunas modificaciones al modelo territorial, con lo cual Colombia pasó a una nueva etapa de su vida institucional que bien puede denominarse la Cuarta República.

Se concluyó entonces que el país no estaba interesado -por ahoraen cambiar el modelo de organización territorial y por ello se optó por mantener el modelo de Estado Unitario con descentralización de sus entidades territoriales, aunque se abrió la puerta para ir creando nuevas entidades administrativas que, gradualmente, con el paso del tiempo, fueran adquiriendo la experiencia y la madurez requerida para transformarlas luego en entidades territoriales que complementaran o sustituyeran a las existentes.

En tal virtud, en cuanto se refiere a este gran tema, el régimen colombiano se enmarca dentro de lo que pudiéramos llamar las Constituciones Catálogo: que tienen una gama de posibilidades para ir escogiendo según las necesidades, el tiempo y el medio. Solo que la Constitución Política de Colombia tiene un "gran catálogo", abigarrado, complejo

A \& C R. de Dir. Administrativo e Constitucional, Belo Horizonte, ano 7, n. 28, p. 167-193, abr./jun. 2007 
y confuso que aún los expertos no saben si su organización se mueve dentro del esquema centralizacióndescentralización; si tiene un régimen autonómico; si más bien consagró las bases para un sistema semifederal cuya definición corresponderá curiosamente al legislador y no al Constituyente; o, si tiene un sistema mixto, sui géneris, en todo caso.

La interpretación que de la Constitución Política ha hecho la Corte Constitucional colombiana hasta ahora se ha inclinado por definir que Colombia aún se mueve dentro del esquema centralización-descentralización. Empero, es apenas una interpretación, la cual puede variar, como varía pendularmente año tras año, la jurisprudencia constitucional colombiana. Otros, siguen pensando con el deseo de algunos constituyentes y creen que Colombia se enmarca en un régimen distinto sin que hasta ahora se haya logrado precisarlo.

En consecuencia, en lo que se refiere al ordenamiento territorial previsto en la Constitución Política Colombiana, no existe un sistema definido, una orientación clara, sino un conjunto de normas de las cuales fluye una abigarrada maraña de entidades que en muchas ocasiones dificultan el cumplimiento de los fines esenciales del Estado o impiden el adecuado ejercicio de las funciones públicas con sujeción a los principios de eficacia y eficiencia mediante la correcta utilización de los recursos técnicos y fiscales y del talento humano.

Lo cierto es que actualmente el país se divide para efectos administrativos en 32 Departamentos, 4 Distritos - Capital y Especiales-, 4 áreas metropolitanas y 1.101 municipios. Además de todos ellos, la Constitución Política de 1991, prevé también la creación de las Regiones como entidades administrativas y de Planificación; la conversión de éstas en Regiones como entidades territoriales; la creación de las provincias como entidades administrativas; la conversión de éstas -también- en entidades territoriales; la conversión o transformación de las áreas metropolitanas en Distritos Metropolitanos; la creación de entidades territoriales indígenas; la creación de localidades en el Distrito Capital y la creación de comunas y corregimientos en los distintos municipios.

En conclusión, de conformidad con lo previsto en la Constitución Política expedida en 1991, se determinó que son entidades del orden territorial, que por lo mismo constituyen el conjunto de entidades descentralizadas territorialmente, las siguientes:

1. Las entidades territoriales. Esto es:

a. El Municipio. El cual constituye la entidad fundamental de la A \& C R. de Dir. Administrativo e Constitucional, Belo Horizonte, ano 7, n. 28, p. 167-193, abr./jun. 2007 
división político-administrativa del Estado, y por lo tanto, el que primero debe impulsarse y consolidarse. Para tal efecto, se expidió la Ley 60 de 1993, sobre participación de los municipios en los ingresos corrientes de la Nación y la definición de sus funciones y los servicios a su cargo; la Ley 100 de 1993, sobre salud pública; la Ley 105 de 1993, modificada por la Ley 336 de 1996, sobre transporte; la Ley 115 de 1994, sobre educación; la Ley 136 de 1994, sobre organización administrativa de los municipios; la Ley 141 de 1994, sobre participación de las regalías; las Leyes 142 y 143 de 1994, modificada por las Leyes 632 de 2000 y 689 de 2001, sobre servicios públicos domiciliarios; la Ley 358 de 1997, sobre endeudamiento de las entidades territoriales; la Ley 388 de 1997, sobre el ordenamiento físico del territorio; la Ley 617 de 2000, sobre organización administrativa, fortalecimiento de la descentralización y racionalización del gasto público; la Ley 633 sobre fortalecimiento de los fiscos territoriales y la Ley 715 de 2001, sobre el nuevo régimen de participaciones de las entidades territoriales en los ingresos corrientes de la Nación.

El proceso de consolidación continúa en medio de muy graves dificultades, mientras que, es por el Municipio, por donde ha comenzado el derrumbamiento de la institucionalidad y de la integridad territorial de Colombia, pues es claro el designio de las organizaciones armadas al margen de la ley para suprimir todo vestigio de vida municipal en sus crecientes áreas de influencia.

Colombia cuenta con 1.101 municipios, 37 de los cuales concentran poblaciones superiores a 100.000 habitantes, mientras que más de 800 concentran en cada uno de ellos menos de 30.000 y poseen una muy escasa capacidad generadora de recursos. Los municipios pequeños representan comparativamente poco si se atiende a sus demografías y economías; pesan poco electoralmente y su representación política es insignificante a escala nacional; empero, cosa grande es el municipio pequeño si se considera su descomunal geografía. Los más "pequeños" son en realidad los más grandes del país, y ellos solos responden por la presencia del Estado en su enorme territorialidad. En contraste con su pequeñez demográfica, son el fundamento físico de la nacionalidad y la sustancia viva del espíritu nacional.

Así, Colombia tiene más territorio que Estado, con el agravante de que el Estado cede cada vez más territorio ante quienes conspiran contra

A \& C R. de Dir. Administrativo e Constitucional, Belo Horizonte, ano 7, n. 28, p. 167-193, abr./jun. 2007 
su existencia.

b.El Distrito. Es una entidad territorial especial que requiere una organización propia y diferente a la de los municipios y con autonomía de los departamentos, para el gobierno y la prestación de los servicios públicos en núcleos urbanos muy grandes, comenzando por la capital del Estado, que al mismo tiempo es la sede principal de las autoridades públicas. En Colombia existen el Distrito Capital de Bogotá, el Distrito Turístico y Cultural de Cartagena de Indias, el Distrito Turístico, Cultural e Histórico de Santa Marta, el Distrito Industrial y Portuario de Barranquilla y los Distritos Metropolitanos que resultarán de la conversión en ellos de las Áreas Metropolitanas, todos los cuales se dividen en localidades que a su vez son entidades territoriales especiales de tales Distritos.

c. El Departamento. Es la entidad a la cual le corresponde cumplir funciones administrativas de coordinación, de intermediación entre la Nación y los Municipios, de complementariedad, concurrencia o subsidiariedad de la acción municipal y de prestación de los servicios que determinan la Constitución y las leyes.

El modelo territorial previsto en la Constitución de 1991, se ha ido desarrollando legislativamente en cuanto se refiere a la acción municipal pero se petrificó en cuanto se refiere a la acción departamental. El departamento no es objeto de una política de Estado desde hace quince años. Su profunda crisis, que hace parte de la crisis general del Estado, radica en este abandono institucional, que produce un impacto negativo en la estructura general de la administración pública y crea problemas adicionales a la gestión municipal, especialmente respecto de los municipios de $4^{\mathrm{a}}, 5^{\mathrm{a}}$ y $6^{\mathrm{a}}$ categorías. Al haberlo dejado a la deriva y en el limbo jurídico (el Código de Régimen Departamental sigue siendo el Decreto 1222 de 1986, que es anterior a la Constitución Política de 1991) no se ha logrado desarrollar una política de ámbito e impacto regional, y se ha producido un vacío institucional en virtud del cual la organización territorial de hecho se ha polarizado entre la Nación y los municipios.

Todo ello ocurre en medio de una incré́ble indiferencia que parte de la idea infundada de que el país, a pesar de su vastedad y complejidad, puede manejarse solo con gobiernos locales y gobierno nacional. También se apuntala en el error de que los departamentos están próximos a desa- 
parecer en virtud de una inminente regionalización de Colombia.

Aparte de que ese futuro tal vez no esté tan próximo, no puede perderse de vista que, cuando en el futuro se creen las regiones que predican los artículos 306 y 307 de la Constitución Política, los departamentos deberán permanecer. A menos, claro está, que sobre este punto decida reformarse la Constitución.

Todo ello indica que es urgente mejorar la estructura y funcionamiento de los actuales departamentos, mientras llega la hora de reformas mayores que los haga formar parte de regiones extensas, o los supriman o los transformen en entes de otra naturaleza.

2. Las entidades descentralizadas, funcionalmente o por servicios.

Se trata de personas jurídicas inferiores a los departamentos, los distritos y los municipios, los cuales tienen a su cargo la ejecución de las políticas públicas que trazan las autoridades de las entidades territoriales y por ello están adscritas o vinculadas a cada una de éstas. Tales entidades son los Establecimientos públicos, las Empresas industriales y/o comerciales, las Empresas Sociales, las Empresas oficiales prestadoras de servicios públicos domiciliarios, las Sociedades entre entidades públicas, las Sociedades de economía mixta y las demás personas jurídicas de derecho público creadas por las Asambleas Departamentales o los Concejos Distritales o Municipales con el carácter de entidades descentralizadas del orden departamental, distrital o municipal, respectivamente.

3. Las entidades administrativas especiales del orden territorial.

Son entidades administrativas que por virtud de la Constitución Política y de ley pueden convertirse o transformarse más adelante en entidades territoriales. Ellas son las áreas metropolitanas, las cuales pueden convertirse en Distritos Metropolitanos (Art. 319); las provincias que pueden convertirse en entidades territoriales (Arts. 286 y 321); y, las Regiones Administrativas y de Planificación, las cuales pueden convertirse en Regiones como entidades territoriales (Arts. 286 y 307).

4. Los territorios indígenas.

Se trata de los territorios que sirven de asiento a las comunidades o pueblos indígenas, gobernados por sus propias autoridades indígenas cabildos indígenas, gobernadores indígenas, etc. -, conforme a sus usos y costumbres, y que también pueden convertirse en entidades territoriales (Arts. 286, 329 y 330).

Este conjunto de entidades del orden territorial es, en todo caso, un catálogo de posibilidades y no una serie de categorías de obligatoria

A \& C R. de Dir. Administrativo e Constitucional, Belo Horizonte, ano 7, n. 28, p. 167-193, abr./jun. 2007 
creación, el cual debe ser utilizado para realizar el proceso de descentralización en forma gradual y no simultánea.

Es más, algunas instituciones son incompatibles con otras. Por ejemplo, cuando un área metropolitana decide transformarse en entidad territorial, desaparece el área metropolitana como entidad administrativa y los municipios que la integran como entidades territoriales, para dar paso a una nueva entidad territorial: el Distrito Metropolitano, el cual se divide en localidades, siendo ellas los anteriores municipios que se anexaron o fueron absorbidos por el nuevo Distrito. Lo mismo sucedería con la Región Administrativa y de Planificación si decide convertirse en una entidad territorial: desaparece la RAP como entidad administrativa y los departamentos que la integran para darle paso a la Región Territorial.

Como se puede observar, lo cierto es que Colombia es un Estado en proceso de construcción territorial.

\section{Los fines esenciales del Estado y los principales principios y} criterios constitucionales que afectan al Derecho Administrativo

A partir de la Constitución Política de 1991, debe distinguirse entre los fines esenciales del Estado, principios que orientan la actividad administrativa y los principios que orientan la organización administrativa.

A) Los fines esenciales del Estado

Estos están previstos a lo largo de la Constitución Política y pueden resumirse en los siguientes:

1.Servir a la comunidad.

2. Promover la prosperidad general.

3. Garantizar la efectividad de los principios, derechos y deberes consagrados en la Constitución.

4. Facilitar la participación de todos en las decisiones que los afectan y en la vida económica, política, administrativa y cultural de la nación.

5. Defender la soberanía, la honra de la nación, la independencia nacional y las instituciones públicas.

6. Defender y mantener la integridad del territorio.

7. Asegurar la convivencia pacífica y la vigencia de un orden justo.

8. Mantener, conservar y restablecer el orden público.

9. Defender el orden constitucional.

A \& C R. de Dir. Administrativo e Constitucional, Belo Horizonte, ano 7, n. 28, p. 167-193, abr./jun. 2007 
10. Conseguir el mejoramiento de la calidad de vida de los habitantes.

11. Conseguir la distribución equitativa de las oportunidades y los beneficios del desarrollo.

12. Preservar el ambiente sano.

13. Asegurar que todas las personas, en particular las de menores ingresos, tengan acceso efectivo a los bienes y servicios básicos.

14. Promover la productividad, la competitividad y el desarrollo armónico de las regiones.

15. Asegurar la prestación eficiente de los servicios públicos a todos los habitantes del territorio nacional.

16. El bienestar general y el mejoramiento de la calidad de vida de la población.

17. La solución de las necesidades insatisfechas de salud, de educación, de saneamiento ambiental y de agua potable.

18. Asegurar el cumplimiento de sus deberes sociales y de los particulares.

B) Los principios orientadores de la actividad administrativa

Para el año de 1982, Colombia no contaba siquiera con los principios que orientan la actuación administrativa a cargo de las autoridades, excepto en lo relacionado con la impugnación en sede administrativa de los actos de carácter particular y concreto y su revocatoria directa, según las normas previstas en el Decreto 2733 de 1959. En tal virtud, en primer lugar, la Ley 58 de 1982, enunció los principios que en lo sucesivo orientarían la actuación y definió el contenido y alcance de los mismos y, posteriormente, el Código Contencioso Administrativo expedido en 1984, se ocupó de precisar tales contenidos, todo lo cual sirvió para que más adelante, en 1991, el Constituyente los elevara a rango constitucional.

Ahora, según la Constitución Política, la actuación administrativa debe sujetarse, entre otros, a los siguientes principios orientadores:

1. Estado Social de Derecho (C.P. Art. 1): Conforme al cual el Estado tiene por finalidad servir a la comunidad, promover la prosperidad general y garantizar la efectividad de los principios, derechos y deberes consagrados en la Constitución Política.

2. Soberanía popular (C.P. Art. 3): Conforme al cual la soberanía reside exclusivamente en el pueblo, del cual emana el poder público. El pueblo la ejerce en forma directa o por medio de sus representantes, en los términos que la Constitución establece.

3. Participación (C.P. Art. 2): Conforme al cual todos los habitantes

A \& C R. de Dir. Administrativo e Constitucional, Belo Horizonte, ano 7, n. 28, p. 167-193, abr./jun. 2007 
tienen derecho a participar en las decisiones que los afectan y en la vida económica, política, administrativa y cultural de la nación. El Estado debe garantizar la participación de las organizaciones de consumidores y usuarios en el estudio de las disposiciones que les conciernen.

4. Supremacía constitucional (C.P. Art. 4): Conforme al cual en todo caso de incompatibilidad entre la Constitución y la ley, se aplican las disposiciones constitucionales.

5. Responsabilidad (C.P. Arts 6, 90, 92 y 124): Conforme al cual los servidores públicos son responsables ante las autoridades por infringir la Constitución y las leyes y por omisión o extralimitación en el ejercicio de sus funciones. El Estado debe responder patrimonialmente por los daños antijurídicos que le sean imputables, causados por la acción o la omisión de las autoridades públicas. En el evento de ser condenado el Estado a la reparación patrimonial de uno de tales daños, que haya sido consecuencia de la conducta dolosa o gravemente culposa de un agente suyo, aquél debe repetir contra éste. Cualquier persona natural o jurídica puede solicitar de la autoridad competente la aplicación de las sanciones penales o disciplinarias derivadas de la conducta de las autoridades públicas. La ley debe determinar la responsabilidad de los servidores públicos y la manera de hacerla efectiva.

6. Primacía de los derechos inalienables de la persona (C.P. Art.5): Conforme al cual el Estado reconoce, sin discriminación alguna, la primacía de los derechos inalienables de la persona.

7. Diversidad étnica y cultural (C.P. Art. 7): Conforme al cual el Estado reconoce y protege las diferentes etnias y culturas existentes en la nación colombiana.

8. Igualdad (C.P. Art. 13). Conforme al cual todas las personas nacen libres e iguales ante la ley, deben recibir la misma protección y trato de las autoridades y deben gozar de los mismos derechos, libertades y oportunidades sin ninguna discriminación por razones de sexo, raza, origen nacional o familiar, lengua, religión opinión política o filosófica. El Estado debe promover las condiciones para que la igualdad sea real y efectiva.

9. No discriminación negativa y sí discriminación positiva (C.P. Art. 
13): Conforme al cual el Estado debe adoptar medidas a favor de grupos discriminados o marginados, debe proteger especialmente a aquellas personas que por su condición física o mental, se encuentren en circunstancias de debilidad manifiesta y debe sancionar los abusos o maltratos que contra ellas se cometan.

10. Protección especial (C.P. Arts. 13, 44, 45, 46 y 47): Conforme al cual aquellas el Estado debe brindar protección especial a las personas que por su condición económica, física o mental, se encuentren en circunstancias de debilidad manifiesta y de manera especial a las mujeres cabeza de hogar, a los niños, a los adolescentes, a las personas de la tercera edad y a los disminuidos físicos, sensoriales y psíquicos, entre otros.

11. Acceso a las autoridades administrativas (C.P. Arts. 23 y 74): Conforme al cual toda persona tiene derecho a presentar peticiones respetuosas a las autoridades por motivos de interés general o particular y a obtener pronta resolución. Todas las personas tienen derecho a acceder a los documentos públicos salvo los casos que establezca la ley.

12. Debido proceso sustancial (C.P. Art. 29): Conforme al cual la conducta de toda persona debe ser analizada, examinada y juzgada con el respeto y el cumplimiento de las garantías y formalidades preestablecidas por la ley, ante autoridad competente y con la observancia de la plenitud de las formas de cada actuación administrativa. La Constitución Política ordena que el principio del debido proceso también se aplica a toda clase de actuaciones administrativas. Es nula de pleno derecho, la prueba obtenida con violación del debido proceso.

13. Defensa (C.P. Art. 29): Conforme al cual toda persona que sea sindicada tiene derecho a defenderse de las imputaciones o incriminaciones que se le hagan ante las autoridades, durante las investigaciones y el juzgamiento administrativo; a presentar o pedir pruebas y a controvertir las que se alleguen en su contra; a impugnar la decisión negativa y a no ser juzgado dos veces por el mismo hecho.

14. Audiencia (C.P. Art. 29): Conforme al cual antes de que se adopte cualquier decisión, el particular tiene derecho a ser escuchado.

15. Doble instancia (C.P. Art. 31): Conforme al cual toda decisión

A \& C R. de Dir. Administrativo e Constitucional, Belo Horizonte, ano 7, n. 28, p. 167-193, abr./jun. 2007 
administrativa puede ser apelada o impugnada, salvo las excepciones que consagre la ley.

16. Contradicción (C.P. Art. 29): Conforme al cual los interesados tienen la oportunidad de conocer y de controvertir las pruebas que existan en su contra y de impugnar las decisiones que los afecten por los medios legales.

17. Favorabilidad (C.P. Art. 29). Conforme al cual en derecho administrativo sancionador, que es expresión de las facultades de inspección, vigilancia y control en ejercicio de las actividades propias de la función de policía administrativa, así como en derecho disciplinario, mediante el cual se analiza la conducta de los servidores públicos, la ley permisiva o favorable, aun cuando sea posterior, se aplica de preferencia a la restrictiva o desfavorable.

18. Presunción de inocencia (C.P. Art. 29 inciso cuarto): Conforme al cual también en derecho administrativo sancionador así como en derecho disciplinario, toda persona se presume inocente mientras no se le haya declarado administrativamente responsable.

19. Conformación, ejercicio y control del poder político (C.P. Art. 40): Conforme al cual todo ciudadano tiene derecho a participar en la conformación y control del poder político para lo cual puede elegir y ser elegido; tomar parte en elecciones, plebiscitos, referendos, consultas populares y otras formas de participación democrática; constituir partidos, movimientos y agrupaciones políticas; revocar el mandato de los elegidos; tener iniciativa en las corporaciones públicas; interponer acciones públicas en defensa de la Constitución y e la ley y acceder al desempeño de funciones y cargos públicos.

20. Buenafe(C.P.Art. 83): Conformeal cual toda persona queacude ante las autoridades lo hace en cumplimiento de los deberes que le impone el orden jurídico para satisfacer las obligaciones que le exige la sociedad, sin malicia, ocultación, intención dañina o provecho indebido.

21. Solidaridad (C.P. Art. 95): Conforme al cual tanto las autoridades como los particulares deben responder con acciones humanitarias ante situaciones que pongan en peligro la vida o 
la salud de las personas.

22. Competencia (C.P., Arts. 121, 122 y 123): Conforme al cual ninguna autoridad del Estado puede ejercer funciones distintas de las que le atribuye la Constitución y la ley. No puede haber empleo público que no tenga funciones detalladas en la ley o reglamento. Ningún servidor público puede entrar a ejercer su cargo sin prestar juramento de cumplir y defender la Constitución y desempeñar los deberes que le incumben. Los servidores públicos están al servicio del Estado y de la comunidad y deben ejercer sus funciones en la forma prevista por la Constitución, la ley y el reglamento.

23. Legalidad (C.P., Art. 123): Conforme al cual toda actuación y decisión administrativa debe cumplirse y adoptarse, respectivamente, en la forma prevista por la Constitución, la ley y el reglamento.

24. Prevalencia del interés general (C.P. Art. 209): Conforme al cual la función administrativa está al servicio de los intereses generales y se desarrolla con fundamento en los principios que la orientan. Las autoridades administrativas deben coordinar sus actuaciones para el adecuado cumplimiento de los fines del Estado.

25. Economía (C.P. Art. 209): Conforme al cual las normas de procedimiento deben ser utilizadas para agilizar las decisiones, los procedimientos se deben adelantar en el menor tiempo y con la menor cantidad de gastos de quienes intervienen en ellos, no se deben exigir más documentos y copias que los estrictamente necesarios, ni autenticaciones ni notas de presentación personal sino cuando la ley lo ordene en forma expresa.

26. Celeridad (C.P. Art. 209): Conforme al cual las autoridades tienen el impulso oficioso de los procedimientos, deben suprimir los trámites innecesarios, utilizar formularios para actuaciones en serie cuando la naturaleza de ellas lo haga posible y sin que ello releve a las autoridades de la obligación de considerar todos los argumentos y pruebas de los interesados y deben adoptar las decisiones en el menor tiempo posible.

27. Eficacia (C.P. Art. 209): Conforme al cual los procedimientos y las actuaciones de las autoridades deben lograr su finalidad, removiendo de oficio los obstáculos puramente formales y 
evitando decisiones inhibitorias.

28. Imparcialidad (C.P. Art. 209): Conforme al cual las autoridades deben actuar teniendo en cuenta que la finalidad de los procedimientos consiste en asegurar y garantizar los derechos de todas las personas sin ninguna discriminación, por lo cual, deben darles igualdad de tratamiento, respetando el orden en que actúen ante ellos y adoptando decisiones objetivas con fundamento exclusivo en el orden jurídico.

29. Publicidad (C.P. Art. 209): Conforme al cual salvo los casos previstos en la Constitución y la Ley, las actuaciones son públicas y las autoridades deben dar a conocer sus decisiones mediante las comunicaciones, notificaciones o publicaciones que ordena la ley.

30. Moralidad (C.P. Arts 88 y 209): Conforme al cual toda actuación pública debe ceñirse a los postulados de la ética y cumplirse con absoluta transparencia en interés común.

31. Prevalencia del interés público o social (C.P. Art. 58): Conforme al cual cuando de la aplicación de una ley expedida por motivos de utilidad pública o interés social, resultaren en conflicto los derechos de los particulares con la necesidad por ella reconocida, el interés privado debe ceder al interés público o social.

32. Rendición de cuentas (C.P. Art. 270): Conforme al cual las autoridades están en la obligación de rendir cuenta pública de su gestión para lo cual, sin perjuicio de las funciones de vigilancia y control estatales, tanto los ciudadanos como las organizaciones sociales tienen derecho a vigilar la gestión pública que se cumpla en los diversos niveles administrativos y sus resultados.

C) Los principios que orientan la organización estatal y la administrativa

Los principios que orientan la estructura del Estado y la organización para el cumplimiento de las diferentes funciones públicas, en todos los niveles, son los siguientes:

1. Estado Unitario (C.P. Art. 1), conforme al cual el Estado es simple y no compuesto, lo que significa que se centralizan en una entidad principal las funciones esenciales entre ellas las políticas que comprende la constituyente derivada y la legislativa, la función judicial y la función electoral, aunque su organización también 
puede ser descentralizada o autónoma para el cumplimiento de funciones administrativas.

Por ser Unitario, el Estado se rige solo por una Constitución Política y las entidades del orden territorial no cumplen funciones constituyente, ni legislativa ni judicial.

2. Separación funcional (C.P. art. 113) en virtud del cual aunque cada uno de los órganos del Estado tiene funciones separadas; cada uno de ellos cumple una función como principal pero puede cumplir otras de manera secundaria. Como ya no existe la separación orgánica sino la separación de funciones, un mismo órgano estatal puede cumplir varias funciones, solo que una será la principal y las demás serán secundarias o transitorias.

Así por ejemplo, el Congreso de la República, además de las funciones legislativa y de control - que son las principales -, puede cumplir también, de manera secundaria, las funciones administrativa, judicial, electoral y disciplinaria, que son funciones principales de otros órganos estatales. A su vez, el Gobierno y la administración, además de cumplir funciones administrativas que constituyen su actividad principal, puede cumplir funciones legislativas cuando se le confieran facultades extraordinarias o en circunstancias especiales previa declaratoria de los estados de excepción. Igualmente, puede cumplir funciones judiciales. Lo propio puede decirse de los jueces, sean ellos corporativos o unipersonales, que además de cumplir su función principal de administrar justicia, pueden también cumplir funciones administrativas relacionadas con la organización judicial.

3. Colaboración armónica (C.P., Art. 113), en virtud del cual, todos los órganos del Estado deben colaborar armónicamente para la realización de los fines comunes del Estado, no obstante, la separación de sus funciones.

4. Centralización (C.P., Art. 1), en virtud del cual las principales funciones de decisión política, administrativa, judicial, fiscalizadora o de control, electoral y de seguridad y defensa nacional se agrupan en la persona jurídica principal de la organización estatal, pudiéndose transferir algunas funciones administrativas a personas jurídicas inferiores o trasladar otras funciones a determinadas personas jurídicas con autonomía administrativa, patrimonial y técnica, sujetas a un régimen constitucional y 
legal propio.

Toda organización descentralizada es al mismo tiempo una organización estatal centralizada, lo que significa que no puede existir descentralización sin centralización y viceversa y que, dependiendo de cada comunidad política, existirá un mayor o menor grado de descentralización. A menor descentralización, mayor es la centralización y a mayor descentralización, menor es la centralización.

5. Descentralización, la cual, en términos generales, supone el traslado, por virtud de la Constitución, la Ley o el reglamento, de una función pública a una persona jurídica - de derecho público o de derecho privado- para que en lo sucesivo la ejerza de manera autónoma y con los recursos que se le entregan para cumplirla o a título de remuneración o compensación, pues al fin y al cabo se trata de la imposición de una carga pública que no se puede soportar ad honorem.

Esta admite varias formas o clases:

"Se puede descentralizar territorialmente (a través de los entes territoriales de los niveles nacional, regional, departamental, municipal, distrital, etc.), funcionalmente o por servicios (a través de los establecimientos públicos, las empresas comerciales e industriales del Estado y las sociedades de economía mixta) y por colaboración (a través de la asignación de competencias a entidades distintas a las anteriores, que pueden ser de naturaleza privada).... conviene consagrar expresamente la descentralización, además de la territorial, la que se hace funcionalmente o por servicios y la que se hace por colaboración, para señalar así los fundamentos que deben regir estos fenómenos". ${ }^{2}$ (Subrayado fuera del texto).

a. La descentralización territorial que consiste en el traslado o atribución de funciones públicas que hace directamente la Constitución, la Ley o el reglamento a personas jurídicas de derecho público del orden territorial y por lo mismo distintas de la entidad central -esto es, la Nación- e inferiores a ésta, las cuales deben ser cumplidas por aquellas con autonomía administrativa, patrimonial y técnica. ${ }^{3}$

\footnotetext{
2 Asamblea Nacional Constituyente. Informe a la Comisión Tercera: Rama Ejecutiva del Poder Público. Gaceta Constitucional, n. 62, p. 11, 29 abr. 1991

3 Una definición jurisprudencial sobre esta modalidad de descentralización se halla contenida en las Sentencias C-216 del 28 de abril y C-497-A del 3 de Noviembre de 1994 proferidas por la Corte
} 
b. La descentralización funcional o por servicios que consiste en el traslado o atribución de funciones públicas o servicios que hace directamente la Constitución, la Ley o el reglamento a personas jurídicas de derecho público de carácter administrativo y por lo mismo distintas de la entidad central e inferiores a ésta, las cuales deben ser cumplidas por aquellas con autonomía administrativa, patrimonial y técnica. Puede ser del orden Nacional cuando se descentraliza de la Nación a sus entidades descentralizadas o del orden departamental, distrital o municipal, cuando se descentraliza del Departamento, el Distrito o el Municipio a sus entidades descentralizadas de carácter departamental, distrital o municipal, respectivamente. ${ }^{4}$

c. La descentralización por colaboración que consiste en el traslado o atribución de funciones públicas que la Ley o el reglamento hacen a personas jurídicas de derecho privado las cuales deben ser cumplidas por éstas con autonomía administrativa, patrimonial y técnica. ${ }^{5}$

Constitucional, en las cuales se lee lo siguiente: "... La palabra 'descentralización' se emplea en sentido genérico y en sentido técnico. De acuerdo con el primero, se le da ese nombre a todo proceso que traslada a asuntos de la capital del Estado a las entidades seccionales o locales, cualquiera que sea su índole; así se habla de descentralización fiscal, económica o industrial. En sentido técnico jurídico, la descentralización significa traslado de competencias de carácter administrativo a manos de autoridades regionales o locales (...). La descentralización se ha entendido como la facultad que se le atribuye a determinadas entidades públicas para gobernarse por sí mismas, mediante el otorgamiento de funciones específicas que son ejercidas autónomamente. Existe ... la denominada descentralización territorial, entendida como el otorgamiento de competencias o funciones administrativas a las entidades territoriales regionales o locales, las cuales se ejecutan en su propio nombre y bajo su propia responsabilidad. Se trata entonces de una situación en la que se le confiere cierta autonomía a las colectividades para el manejo de sus propios asuntos; autonomía que debe ser comprendida desde un aspecto administrativo y financiero, lo cual no significa que las autoridades locales se aparten del control ejercido por el poder central".

4 También en las Sentencias C-216 del 28 de abril y C-497-A del 3 de noviembre de 1994, la Corte Constitucional señaló sobre ella lo siguiente: "La llamada descentralización por servicios, implica el otorgamiento de competencias o funciones administrativas a entidades que se crean para ejercer una actividad especializada. Por ello, el artículo $1^{\circ}$ del Decreto 3130 se refiere a los establecimientos públicos, las empresas industriales y comerciales del Estado y a las sociedades de economía mixta, como entidades descentralizadas, pues se trata de entidades que desarrollan una actividad específica, con autonomía financiera y administrativa y bajo el control del poder central, también llamado 'control de tutela'.".

5 En la Sentencia C-308 del 7 de julio de 1994, la Corte Constitucional, consideró que la descentralización por colaboración es una de las expresiones más genuinas de la democracia participativa. Dijo entonces que: "Es sabido que la atención de los servicios que presta el Estado puede cumplirse directamente por las autoridades del nivel central o utilizándose mecanismos de gestión por descentralización, que pueden asumir las autoridades regionales (descentralización territorial) o los organismos descentralizados por servicios (descentralización técnica), pero que, además, también puede lograrse mediante la participación del sector privado con ocasión de un traslado de facultades. Eso lo define la naturaleza del servicio o las razones de conveniencia, es decir, la posibilidad de transferir y radicar competencias y las ventajas que esas transferencias signifiquen en la prestación del servicio. / La intervención de los particulares en la gestión de servicios estatales es una de las expresiones más genuinas de la democracia participativa, porque hace 
La descentralización por servicios como la descentralización territorial, suponen el traslado o atribución de funciones entre sujetos de derecho público; en cambio, en la descentralización por colaboración, la atribución de funciones se hace en un particular, sin obtener su previo consentimiento o aceptación, por lo cual a partir de ese momento, debe asumir un deber o una carga que en todo caso no puede ser desproporcionada, excesiva y contraria, por lo mismo a la equidad y a la justicia, puesto que si lo es, no está obligado a soportarla sin contraprestación.

6. Desconcentración, en virtud del cual, estando centralizadas algunas funciones públicas en cabeza de la persona jurídica principal de la organización estatal, ellas deben ser distribuidas para efectos de su ejercicio, al interior de esa misma persona jurídica en varias dependencias suyas, las cuales se organizan con autonomía administrativa y financiera. Así por ejemplo, la función legislativa que se centraliza en el Congreso de la República que es parte de la persona jurídica central -la Nación-, se desconcentra para efectos de su ejercicio en dos cámaras y éstas a su vez, en comisiones constitucionales, legales y especiales.

7. Coordinación, en virtud del cual, ante las diferentes funciones a cargo de cada una de las autoridades administrativas, éstas deben coordinar sus actuaciones paras el adecuado cumplimiento de los fines del Estado.

8. Dirección, en virtud del cual, las autoridades superiores de la administración deben adoptar las medidas, directrices y políticas que correspondan para que sean cumplidas y ejecutadas por las entidades inferiores.

9. Control, en virtud del cual, cada autoridad está sujeta a la inspección, vigilancia y control de otras, que puede ser político, administrativo, judicial, fiscal o disciplinario, sin perjuicio del control social y del control ciudadano.

real uno de los fines esenciales del Estado que consiste en 'facilitar la participación de todos en las decisiones que los afectan y en la vida económica, política, administrativa y cultural de la Nación' (C.P. art. 2), y, además, permite involucrar en la acción pública a los propios sectores comprometidos e interesados en la prestación del servicio. Y es, por todo ello, una de las formas que adopta la descentralización administrativa, doctrinariamente reconocida como 'descentralización por colaboración'. / Se busca de esta manera, por razones de eficiencia administrativa, el traslado de las competencias y funciones estatales hacia los beneficiarios del servicio y el acceso a su ejecución de personas que posean medios técnicos o especiales conocimientos en la gestión empresarial". 
10. Subsidiariedad, en virtud del cual una entidad pública, debe suplir la actividad de otra que no pueda o no esté en capacidad de cumplir las funciones y cometidos a ella atribuidos. Así por ejemplo, el Departamento asume los servicios que los municipios no pueden cumplir.

11. Complementariedad, en virtud de la cual una entidad pública debe complementar la actividad de otra u otras, para el mejor cumplimiento de los cometidos estatales. Así, por ejemplo, el Departamento complementa la acción del Municipio en la prestación de los servicios públicos.

12. Intermediación, en virtud del cual una entidad pública sirve de enlace entre dos entidades de distinto nivel administrativo. Así por ejemplo, el Departamento intermedia entre la Nación y el Municipio. La provincia intermedia entre el Departamento y el Municipio.

13. Concurrencia, en virtud del cual una o varias entidades concurren simultáneamente en el ejercicio de la función pública para la realización de los cometidos estatales. Así, por ejemplo, en materia de salud, educación y saneamiento básico, la Constitución determina competencias concurrentes entre la Nación, los Departamentos y los Municipios.

14. Autonomía, envirtud delcual, existen entidades públicas, sujetas a un régimen constitucional y legal propios que para el ejercicio de sus funciones requieren autonomía administrativa, patrimonial y técnica, lo cual significa que no están sujetas a la dirección, coordinación y control de otros órganos o autoridades administrativos. Así, por ejemplo, el Banco de la República, no está sujeto al control, dirección y tutela administrativa del Gobierno.

\section{Análisis de las instituciones del Derecho Administrativo que han sido elevadas a rango constitucional}

La determinación de buena parte de la estructura del Estado, de sus funciones, atribuciones y competencias, especialmente de la Rama Ejecutiva del Poder Público, tanto del orden nacional como del orden territorial, en la forma atrás descrita, que eran temas regulados principalmente por la ley y objeto de estudio en Derecho Administrativo, ahora

A \& C R. de Dir. Administrativo e Constitucional, Belo Horizonte, ano 7, n. 28, p. 167-193, abr./jun. 2007 
son objeto de regulación constitucional y objeto de estudio tanto del derecho constitucional como del derecho administrativo.

Lo mismo ha sucedido con los principios que orientan la actividad administrativa y los principios de la organización administrativa, también ya descritos, los cuales no solo tienen ahora una previsión normativa en la propia Carta Política sino un amplio desarrollo constitucional por vía jurisprudencial.

Este es un ejemplo más de la constitucionalización del derecho administrativo, del tratamiento uniforme del derecho público, puesto que derecho constitucional y derecho administrativo configuran una unidad indisoluble e inseparable, motivo por el cual se reafirma que no hay derecho administrativo sin derecho constitucional ni puede existir derecho constitucional sin derecho administrativo.

\section{Bibliografía}

BREWER CARIAS, Allan. Principios del procedimiento administrativo en América Latina. 1. ed. Bogotá: Legis; Universidad del Rosario, 2003.

CASSAGNE, Juan Carlos. Derecho administrativo. 7. ed. Buenos Aires: Abeledo-Perrot Lexis Nexis, 2002. t. 1, 2.

GACETA CONSTITUCIONAL. Bogotá D.E.: Asamblea Nacional Constituyente, 1991.

GACETA DE LA CORTE CONSTITUCIONAL. Bogotá D.C., 1992-2000.

GACETA DEL CONGRESO DE LA REPÚBLICA. Bogotá D.C.: Imprenta Nacional, 19922003.

GARCÍA DE ENTERRÍA Eduardo; RAMÓN FERNÁNDEZ, Tomás. Curso de derecho administrativo. Madrid: Civitas, 2002. t. 1, y 2.

GARCIA DE ENTERRIA, Eduardo. Democracia, Jueces y Control de la Administración. $5^{\mathrm{a}}$ edición. Editorial Civitas S.A., Madrid, 2000.

GARRIDO FALLA, Fernando. Tratado de derecho administrativo: volumen III: la justicia administrativa. 1. ed. Madrid: Tecnos, 2001.

GORDILLO, Agustín. Después de la Reforma del Estado. Buenos Aires: Fundación de Derecho Administrativo, 1996.

IBAÑEZ NAJAR, Jorge Enrique. Estudios de derecho administrativo. 1. ed. Bogotá: Javegraf Ediciones de la Pontificia Universidad Javeriana, 2005.

IBAÑEZ NAJAR, Jorge Enrique. Estudios de derecho constitucional económico. 1. ed. Bogotá: Javegraf Ediciones de la Pontificia Universidad Javeriana, 2002.

MUÑOZ MACHADO, Santiago. Tratado de derecho administrativo y derecho público general. 1. ed. Madrid: T. I. Civitas, 2004.

A \& C R. de Dir. Administrativo e Constitucional, Belo Horizonte, ano 7, n. 28, p. 167-193, abr./jun. 2007 
PARADA, Ramón. Derecho administrativo. 10. ed. Madrid: Marcial Pons Ed. Jurídicas y Sociales, 1999. t. 1, 2, 3.

PAREJO ALONSO, Luciano; JIMÉNEZ BLANCO, Antonio; ORTEGA ALVAREZ, L. Manual de derecho administrativo. 5. ed. Barcelona: Ariel, 1998. t. 1, 2.

PÉREZ ESCOBAR, Jacobo. Derecho constitucional colombiano. 5. ed. Bogotá: Temis, 2000.

PEREZ ROYO, Javier. Curso de derecho constitucional. 9. ed. Madrid: Marcial Pons, 2003.

RODRIGUEZ RODRIGUEZ, Libardo. Derecho administrativo general y colombiano. 13. ed. Bogotá: Temis, 2002.

SANTOFIMIO GAMBOA, Jaime Orlando. Tratado de derecho administrativo: T. II: acto administrativo. 4. ed. Bogotá: Universidad Externado de Colombia, 2003.

VIDAL PERDOMO, Jaime. Derecho administrativo. 12. ed. Bogotá: Legis; Universidad del Rosario, 2004.

Informação bibliográfica deste texto, conforme a NBR 6023:2002 da Associação Brasileira de Normas Técnicas (ABNT):

IBÁÑEZ NAJAR, Jorge Enrique. El derecho público colombiano. In: FORO IBEROAMERICANO DE DERECHO ADMINISTRATIVO, 5., 2006, Ecuador. A\&C Revista de Direito Administrativo e Constitucional, Belo Horizonte, ano 7, n. 28, p. 167-193, abr./jun. 2007. 